\title{
The Ethics of Noncompete Clauses
}

\author{
Harrison Frye \\ University of Georgia
}

\begin{abstract}
Noncompete clauses (NCCs), or agreements by employees to not work for a competitor or start a competing business, have recently faced increased public scrutiny and criticism. This article provides a qualified defense of NCCs. I focus on the argument that NCCs should be banned because they unfairly restrict the options of employees. I argue that this argument fails because it neglects the economist Thomas Schelling's insight that limiting exit options can be beneficial for a person. This employee-based defense of NCCs does not absolve all their uses, but it does give us a rough test for evaluating the permissibility of NCCs. With this test in hand, I turn to some of the more controversial uses of NCCs. For those who weigh heavily the interests of employees, the question is not whether NCCs, but when.
\end{abstract}

KEY WORDS: noncompete clauses, employees, employment ethics, freedom, negotiation

\begin{abstract}
$\mathrm{A}$ $\mathrm{n}$ increasingly scrutinized trend within the United States is the rising use of noncompete clauses (NCCs), or covenants not to compete, in employment contracts. ${ }^{1}$ NCCs hold that an employee may not work for a competitor or start a competing business within a certain period of time and geographic area after leaving their firm. On their face, such covenants subject employees to restrictions that many find onerous and unfair. Infamously, the sandwich restaurant chain Jimmy John's required its sandwich artists to sign such agreements, a practice they ended in 2016 after much public and legal criticism (Niswanatha 2016).

Elizabeth Anderson suggests noncompete clauses give employers a way to “imprison workers' human capital” (2017a, 66). Economist Paul Krugman similarly suggests that "things like noncompete clauses ... don't just reduce your wages. They also reduce your options if you're mistreated" (2018). For both Anderson and Krugman, noncompete clauses are symptomatic of the unequal relation between employees and employers. Worse still, such restrictions exacerbate this unequal power relation by restricting the options employees have. In light of such worries, many states are considering passing laws that would severely limit the enforceability of NCCs. For example, Pennsylvania is currently considering such a bill. ${ }^{2}$ If this bill were to pass, Pennsylvania would join states, such as California and Montana, that ban NCCs in all but a few circumstances. More ambitiously, a range of labor groups and politicians seek to convince the US Federal Trade Commission to ban NCCs across the United States (Eidelson 2019).
\end{abstract}

\footnotetext{
1 While the geographic area of focus here and elsewhere in the article is the United States, NCCs are not unique to the US. I will note where my arguments depend on US context. Later discussions also allude to other contexts.

2 Pennsylvania House Bill 171, regular session 2019-20.
} 
I am sympathetic to the suspicion surrounding NCCs. That being said, I worry that the push to legally abolish such restrictions rests on an incomplete analysis. It is true that such restrictions often serve to advance the interests of employers over those of their employees. Further, I grant that employers tend to exploit market power asymmetries in pressing employees to agree to said restrictions. But this does not allow us to conclude with Anderson, for instance, that "every state should follow California's example and ban noncompete clauses from work contracts" (2017b). To be justified in reaching the abolitionist conclusion, we need to investigate whether anything can be said in favor of such covenants before taking them as evidence of hierarchy and domination within the employment relation as Anderson would have us. If we can find something to say in their favor that takes seriously the worries posed by Anderson and others, this allows us to describe conditions under which such restrictions are permissible.

Despite growing public attention to NCCs, ethicists have yet to place the ethics of them under direct scrutiny. This article seeks to start a conversation on this topic by providing a qualified defense of NCCs, going against the grain of much public skepticism. In the legal scholarship, defenses of NCCs tend to focus on benefits to the employer in the form of retaining clients or protecting confidential business information (see Harlan 1960, 667-74). In contrast, I take, as my starting point, Adam Smith's dictum that, in conflicts between the interests of workers and their employers, favoring the interests of workers is "always just and equitable" (Smith 1976, chapter $10,158)$. The idea is that, if we can find a case for NCCs that focuses on the interests of employees, generally speaking, this provides a set of conditions under which such a restriction is permissible. This sort of argument avoids the worries raised by Anderson and Krugman that these clauses unfairly privilege the interests of employers.

Much of the public reaction against NCCs arises from particular cases, as when companies like Jimmy John's require low-wage, low-skill workers to sign NCCs. However, there are other cases that seem less worrisome. Consider, for example, the high-skill, specialized software engineer who signs an NCC in exchange for a wage premium over the course of her career. It is not obvious anything has gone awry in this sort of a negotiation. If you pay attention to the differences between these two sorts of cases, I suggest that what comes out is that NCCs as such are not objectionable. Instead, the problem with NCCs is not that they are used but more often how they are used.

Ultimately, I argue that the error the abolitionist makes is assuming that restrictions are always bad for the person being restricted. In the case of NCCs, for instance, the assumption is that limiting exit options sets back an employee's interests. However, as noted most famously by the economist Thomas Schelling (1960), sometimes limiting an option to exit actually improves an employee's position. Based on this, I argue that NCCs can be a tool for employees to advance their interests in the context of bargaining.

The structure of my argument is as follows. Section one provides a brief overview of NCCs. Section two describes the reasons why many oppose NCCs. Sections three through five show that the basic case against NCCs rests on an error. That being said, this allows me, in section six, to derive a set of ethical conditions to evaluate the use of NCCs. Section seven provides a conclusion. 


\section{NONCOMPETE CLAUSES: A PRIMER}

As noted in the introduction, an NCC is a clause in an employee contract that states that an employee will neither work for a competitor nor start a competing business within a certain time frame and geographical region. NCCs are not a niche piece of legal technology seldom used, but impact a wide range of employees. A recent study of the US labor force suggests that 20 percent of workers were subject to an NCC in 2014, and that 40 percent of workers have signed an NCC over the course of their careers (Starr, Prescott, and Bishara 2018).

NCCs have not always been so widely permitted. In the common law tradition, there is a presumption against acts and covenants that limit competition, or "restraints of trade" (Blake 1960, 626). While there is only a presumption against restraints on trade, restraints placed by "masters" on their workers faced a particularly high burden. Most notably, the Dyer's Case of 1414 in England held that a covenant forbidding a dyer (the defendant) from competing with the plaintiff was void. Evidence suggests that the defendant was a journeyman, or an apprentice, to the plaintiff (Blake 1960, 636). If this is true, concern with how NCCs treat employees played a key role in public reception from early on. Only in the late nineteenth and early twentieth century did NCCs become permissible in their modern form (Blake 1960, 645-46).

Because NCCs are so restrictive, US courts are very hesitant to enforce them. In particular, courts tend not to enforce NCCs when there is no consideration (Perillo 2003, 656-62). That is, these courts look and see if the employer gives something to the employee in exchange for signing the NCC. If an employer requires an employee to sign an NCC after signing an employment contract, and offers no additional benefits or salary, that NCC is likely unenforceable. Further, US courts tend not to enforce NCCs if they are unreasonable in geographic and temporal scope. The burden is on the employer to show that the NCC is narrowly tailored to protect a legitimate business interest. Finally, an employee can avoid an NCC depending on the reasons for leaving a firm. For example, if the employer is guilty of breach of contract or wrongfully terminates the employee, US courts will not enforce the NCC.

Beyond these general common law rules, statutory differences between countries and states impact the validity and enforceability of NCCs. In the United States, for example, various states have enacted statutes drastically limiting the use and enforceability of NCCs. California only allows the use of NCCs in very particular circumstances, such as the sale of a business. But many states permit and enforce NCCs. ${ }^{3}$

\section{THE BASIC CASE AGAINST NONCOMPETE CLAUSES}

The common argument in favor of NCCs rests on the employer's interest. Employers use NCCs as a way of protecting themselves from employees taking trade secrets or 
other vital information with them to competing firms. Similarly, employers use NCCs as a way of protecting their client lists. An employee may leave a firm and take with them those customers the employee interacted with through the firm. Thus, firms argue that NCCs protect legitimate business interests and, for that reason, are a permissible legal tool to use in the pursuit of profit.

But consider the case of Jimmy John's from the introduction. It is difficult to see how Jimmy John's is protecting itself from the transmission of trade secrets through its NCCs for its sandwich artists. Other details of the case raise further questions about the fairness of these agreements. Employers would have employees sign an NCC after accepting an offer of employment, often on the first day of work. Employees did not have access to legal counsel, and these NCCs tended to be unenforceable either due to violating common law restrictions or restrictions set by statute. The particulars of the Jimmy John's case do not suggest the protection of legitimate business interests, but instead suggest the abuse of NCCs to intimidate workers.

More generally, there are a variety of ways NCCs set back the interests of employees. 4

First, NCCs set back employees' interests in general. If an employee is subject to an enforceable NCC, that employee is no longer legally able to seek outside offers without paying a hefty cost of spending a year or two outside of his or her preferred profession. This sets back an employee's interest absolutely to the extent it prevents that employee from seeking alternative, more preferable employment. For example, an employee may accept a job offer they find merely acceptable (the old saw about a bird in the hand) but then, because the job requires an NCC, this employee is now unable to seek a job they would prefer more. This leaves them worse off than they would be sans the NCC. ${ }^{5}$ Let us call this the objection from general employee welfare.

Second, NCCs prejudice employees' interests vis-à-vis their employers' interests by tipping the scales of bargaining power. If an employee is subject to an NCC, they are unable to seek offers from other employers. Lacking credible alternative options, an employee is less likely to be successful in pressing their current employers for a raise or other sorts of benefits. You can see this sort of concern with NCCs when Najah Farley, a senior attorney at the National Employment Law Project, states that noncompete agreements "diminish a worker's power to change jobs and bargain for higher wages by stopping workers from moving between jobs" (2019). Indeed, there is some empirical evidence in the US context to believe that NCCs depress wages under certain conditions (Balasubramanian et al. 2018; Starr 2019). This is the sort of empirical finding we should expect based on this objection. Let us call this the objection from tipping the scales.

Third, NCCs render employees vulnerable to domination. This appears to be Anderson's primary concern regarding NCCs $(2017 \mathrm{a}, 66)$. When you limit the exit 
options of employees, this not only improves the employer's bargaining power, but also makes the job more important for the employee. If I know I cannot work for a competitor or set up my own competitive business, I am going to do what I can to keep my current job. This is especially true against a background of at-will employment (Anderson 2015, 59). The conjunction of the fact that employees are subject to the will of their employer with the fact that an NCC entails that if they are fired their fundamental interests are dramatically set back means that NCCs subject employees to the arbitrary power of their employers. Such subjection is domination (Pettit 1997; Lovett 2010; Taylor 2017). Let us call this the objection from domination.

And finally, and perhaps most simply, NCCs reduce an employees' freedom, understood negatively. On this view of freedom, a person's overall freedom is related to the number of non-interfered options that person has (Carter 1999). NCCs reduce employees' non-interfered options and thus their freedoms. Krugman explicitly raises this worry when discussing how noncompete clauses "reduce or limit your options" (2018). A number of prominent versions of liberalism hold that there is a natural presumption in favor of liberty, or the fact that some course of action restricts freedom is prima facie objectionable (Feinberg 1984, 4; Benn 1988, 87). If these views are correct, then NCCs are prima facie objectionable because they limit options. ${ }^{6}$ Let us call this the objection from limiting options.

It is important to stress that these objections focus on the adverse effects of NCCs on employees and not on what possible effects NCCs have on society, generally speaking. There may be efficiency concerns for and against NCCs, but I set these aside here as outside the scope of this article. Even if efficiency speaks for or against NCCs, most do not think efficiency alone resolves the ethical issue (Satz 2010, 33-5; Preiss 2014; Singer 2018a; Singer 2018b).

\section{MORE CHOICE IS NOT ALWAYS BETTER}

I will return to the objections outlined in section two later in section five. Before doing so, it is worth scrutinizing a general feature of these objections. Most of the employee-based arguments against NCCs turn on an implicit claim that reducing exit options sets back employees' interests. This is either direct, as in the objection from limiting options, or indirect, as in the objection from tipping the scales. Simply put: lacking an exit option is worse for the employee. Or so these arguments suggest.

I will argue this move is too quick. The lack of an exit option is not always disadvantageous. Indeed, there can be good reasons to prefer not having an exit option. When bargaining with others, sometimes the fact that one party cannot retreat allows them to do better by the bargain than they might have been able to 


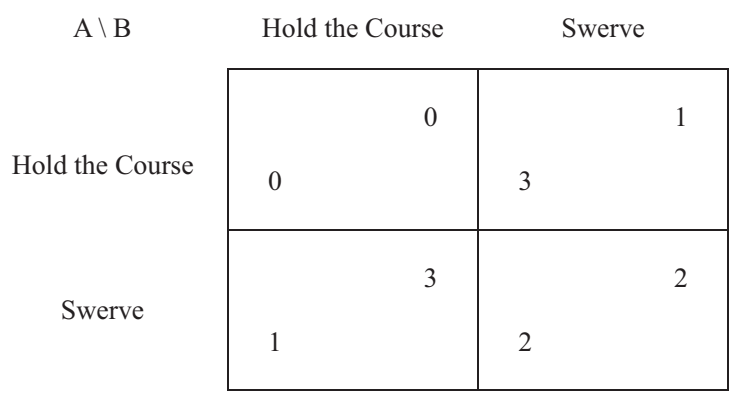

Figure 1: Chicken

otherwise. I suggest that this general principle has some validity in the case of NCCs. This argument will develop over the next two sections. In this section, I draw on work by Schelling, as well as work by the philosophers Gerald Dworkin and J. David Velleman, to establish the general principle that an exit option is at times disadvantageous. In the next section, I apply this to the case of NCCs. But first, let me explain the general point.

Let me begin with a simple example. Suppose you are in a game of chicken. The game of chicken involves two players on a collision course with one another. Each player has two choices: hold the course or swerve aside. You win if you hold the course while your opponent swerves. You lose if you swerve while your opponent holds the course. You also lose if you swerve while your opponent swerves, but not as badly (both of you are chickens, but at least your opponent does not advance over you). You really lose if you hold the course while your opponent does so as well, and you crash into each other. A game table with payoffs representing this preference ranking is reproduced in Figure 1.

As Schelling points out, one way to get ahead in the game of chicken is to reduce your own options $(1960,24)$. Suppose player A could no longer swerve (he makes a show of throwing his steering wheel out the window). What this means for B is that he either keeps the course and crashes into A (disaster!), or swerves and avoids collision (not good, but better than a disaster!). B, being no dummy, swerves and avoids the collision. A stays the course while B swerves. A gets his most preferred option.

Common advice says don't burn your bridges. However, this toy game shows that sometimes you should burn your bridges. Limiting your options can induce others to act as you would prefer. This is most obviously seen in cases of negotiation. If I am negotiating for a used car on behalf of someone else, and that someone else has authorized me to only go to a certain price point, this knowledge limits what the car salesman can push for compared to the case where I do not have a limited budget. By placing limits on a negotiator, a buyer limits her ex ante options (the set of prices she is able to offer) in order to capture ex post benefits (a lower price than she would have gotten if all prices were available to her).

It is not just in negotiations and adversarial situations that having fewer choices can be advantageous. Consider prisoner's dilemma-type situations, where individual 
choices can lead to socially suboptimal situations. ${ }^{7}$ One way to solve such problems is to eliminate people's options to defect in the first place. Consider, for example, workers seeking better pay. It may be in the workers' collective interest to cooperate with one another to strike for better pay. However, each individual worker has an incentive to work while reaping the benefits of others' striking. But, if every worker acts as such, no one strikes and everyone is worse off than they could be otherwise. Because of this, it is not surprising strikes often utilize coercion to eliminate the option of working, as a way of overcoming the collective action problem (Olson 1971, 71).

Finally, as Dworkin points out, having an option can make one worse off outside of strategic bargaining scenarios and collective action problems (Dworkin 1982, 55-6). Velleman uses the example of a night cashier to make this point (1992, 671). The night cashier may not want access to the safe because having that option makes her a target to burglars. Having certain options can simply make a person worse off, in this sense. No one wants to be a target for burglary-if granting an option succeeds in accomplishing that (and only accomplishing that), that option is an option we would rather not have.

I could go on, but I hope the general point is clear enough at this juncture: More is not always better than fewer in the land of options. Indeed, more is sometimes worse.

\section{NONCOMPETE CLAUSES AS COMMITMENT DEVICES}

The general lesson of the last section was that having more options is not always a good thing for a person. There are even situations where having more options makes a person worse off. To be clear, more options does not always make a person worse off. I am not even sure if having more options often makes a person worse off. Because of this, I do not want to overstate the general point. Nonetheless, the point stands. What this section does is extend this point to the case of NCCs. NCCs limit exit options of employees. The question is: Can this be advantageous for employees?

My view is that NCCs can be advantageous for employees for the sorts of reasons outlined in the previous section. NCCs can act as a commitment device. In this way, NCCs are very much in the vein of a Ulysses contract (Elster 1979). The name comes from an episode in Greek/Roman mythology in which Ulysses asked his sailors to tie him to the mast. Ulysses does this so he can listen to the song of the sirens without succumbing to it and jumping to his doom. Ulysses' contract eliminates his exit option in order to advance his interests. Similarly, an NCC, by eliminating an exit option, may advance the interests of an employee. I suggest NCCs can do so in two ways.

First, NCCs can act as a costly signal. By forgoing the option to seek employment outside the firm, employees take on a cost to themselves. Further, NCCs do not 
impose any old cost, but a significant cost. Giving up the chance to seek potentially better offers is a heavy one. Thus, NCCs allow employees to send a credible signal of commitment. Why might this matter?

Firms may have different cultures that reflect different values. You can see how this plays out in different pay scales (Moriarty 2011, 40; Moriarty 2016, 445). Some firms opt for a more competitive, tournament model, where some employees get paid much more than others. Others operate using a more egalitarian, flat distribution of pay. The idea is that some firms opt for a more "relational" model while others for a more a "transactional" model (Macneil 1995; Kalleberg and Rognes 2000). The former rests on metaphors of friendship and family, and focuses on commitment. The latter is less personal and treats the firm as "just a job" and nothing more.

Different firms adopt these different models of organization for different reasons, but an important aspect is that these different models seek different sorts of employees. A relational firm wants employees to invest and commit to their firms. Conversely, different employees have different preferences over firm cultures. Some employees just want a job. Others may want a more relational versus an egalitarian atmosphere. Others still may want the advantages of being in a relational organization culture (e.g., less turnover, more benefits), but really want to treat the job in a transactional manner and leave the job when the next, better offer comes up. ${ }^{8}$

This last category generates a problem for relational firms. Relational firms want committed employees, but it is difficult to separate out those potential employees, who genuinely want a relational firm, from those who simply wish to take advantage of a firm's relational culture. It is cheap talk to express a desire to work at a particular sort of firm. Thus, employees and employers face a signaling problem: What counts as a credible signal of commitment by potential employees? This is where an NCC comes in. An NCC, by making exiting more expensive, is a costly signal that one is committed to the firm. If an employee was only in it to exploit the benefits of a relational firm, that employee may not be willing to forgo a shot at a better alternative. Willingness to forgo the potential of better options down the line is likely good evidence of commitment.

A critical reader might object to this costly signaling story on the grounds that, because NCCs involve the threat of legal coercion, NCCs do not establish wholehearted commitment. For example, consider a marriage where, prior to wedding, the wife makes the husband sign an agreement that, should he cheat on her, he would owe her damages. Undoubtedly, the threat of coercive sanctions deters adultery, but it does not follow that the husband's commitment is wholehearted. Similarly, one might point out that it does not follow from the fact that a person willing to sign an NCC is committed to the firm in a wholehearted manner. Perhaps the only reason a worker signs an NCC is because that worker has no other employment options. Such a worker would, all things being equal, prefer to work at a transactional firm and avoid signing an NCC, but her options are such that the choice she has is between a 
firm with an NCC or unemployment. In such a case, it would be a mistake to infer from the fact that this particular worker is willing to sign an NCC that she wishes to work at a firm for many years. Thus, NCCs can fail to separate on type.

In response to the first concern about coercion and commitment: The problem with this objection is that it focuses on the ex post relationship as opposed to the ex ante one. ${ }^{9}$ The question a costly signal answers is: How do we distinguish type before entering into a relationship? Marriage itself is a costly signal in just the manner I am discussing here. When you marry someone, you limit your exit options from a relationship. This is not just in terms of social costs, but also legal ones. You cannot just "break up" with your spouse, but must go through legal proceedings that may end up being coercive in nature. The fact that one is willing to tie one's hands through marriage provides ex ante evidence of commitment. This remains true even if tying one's hands subjects one to sanction after the fact. This leads to the second issue raised above: Can we really infer from the fact that one is willing to tie one's hands ex ante that one is the committed type?

In response: to say NCCs can function as a costly signal of type does not entail that they are a perfect signal of type. The idea is that, all things being equal, a person's willingness to tie his/her hands to join a firm is evidence that person is committed to that firm in a long-term manner. Of course, all things are not always equal. For example, just because someone is willing to buy an expensive engagement ring (a costly signal!) does not entail that person is wholeheartedly committed to marrying. Perhaps person A prefers being in a relationship over being single. A also prefers a noncommittal relationship over a committed one. However, only person B is willing to be in a relationship with A. Further, B will be in a relationship with A if, and only if, A proposes to B with an engagement ring. Even if an engagement ring would not be a good signal of commitment in this particular case, it would still be reasonable to take engagement rings in general as a sign of a person's commitment. It works similarly for NCCs: an NCC as a costly signal may reveal type probabilistically, even if it is not a perfect indicator of type. An interesting implication of going through this case is that, the more options employees have, the more likely an NCC is to separate on type.

Thus, the first way NCCs can benefit employees is they can act as a costly signal to match employees with employers with similar cultural preferences. Employees who prefer a relational culture can credibly signal this preference to firms with a relational culture.

The second way NCCs can benefit employees is that they make it less costly for firms to invest in training for their employees (Rubin and Shedd 1981). 
Suppose a firm hires an employee. Part of the firm's cost in hiring the employee is not just wages, but also the resources it takes to train the employee. The problem is that a firm's investments into training are sunk costs that cannot be recouped. The employee, once equipped with skills, may now command a premium by working for another firm. This is because the other firm can hire the newly trained employee without expending resources on training. Thus, the threat of exit renders training, under particular circumstances, risky and costly to firms. Under such circumstances, firms may opt for more experienced employees rather than expend resources on a flight risk.

An NCC gives employees a way around this problem. Much like in the case of employees trying to signal their type, an employee requiring training can simply forgo the option of exit through an NCC. If the employee cannot legally work for a competitor without paying significant costs, there is little threat that the employee will exit for greener pastures as soon as training is over. This is advantageous to employees for two reasons.

First, NCCs designed to protect against the risk of poaching after training give opportunities for employees to acquire human capital. By lowering the expected cost of training, NCCs incentivizes employers to train their employees. To the extent that employees value additional skills and human capital, this is a benefit to them. Admittedly, this upside of NCCs is muted by the fact that presumably one of the chief benefits of human capital is the ability to take advantage of the labor mobility that tends to come with it. However, human capital can be advantageous intrafirm and not just interfirm. Further, increased human capital may be beneficial in and of itself. The ability to develop one's own skills, particularly in relation to work, may contribute to one's well-being or self-respect (Rawls 1999, 426; Moriarty 2009).

Second, NCCs may allow employees to get jobs they otherwise could not. Here are two scenarios where this might be the case. First, if a firm is too skittish to hire an employee who lacks the relevant skills absent an NCC, that means the employee who lacks skills is not going to get the job. Thus, for unskilled workers, an NCC can mean the difference between employment and unemployment. Second, by reducing the average expected cost of training, NCCs open up more resources to hire more workers. If a firm knows that some portion of its trainees will be poached by competing firms after training, it will include this expected cost in its hiring decisions. Thus, a firm may expect hiring employees to cost more than it would with an NCC, likely leading to either reducing hiring rates or substituting with technology.

Thus, the second way NCCs function is as a commitment device. In light of the cost of training, NCCs give employees a way to credibly commit to firms and incentivize investment in training.

Before moving on to the next section, it is worth acknowledging a possible concern. You may grant that NCCs can act as a commitment device, but wonder about alternative commitment devices. For example, you could imagine wage garnishment, or the withholding of wages, playing a similar role to NCCs as a commitment device. If I opt to receive only a portion of my wages for a defined period of time, this suggests I have good reason to work beyond that period of time. 
The significance of alternative commitment devices to my argument is that they raise the comparative question of how well NCCs act as commitment devices relative to the alternatives.

I cannot fully deal with this question here, but briefly: It is true that a complete evaluation of NCCs would consider comparing NCCs with other alternatives. But before we can engage in such a comparison, we need to grasp what can be said in favor of NCCs on their own terms. This is what I am trying to do in this article. Later work can build on what I say here to develop a full evaluation of the practice. That being said, the comparative question is much less obvious than presumed. For example, while wage garnishments may be effective for those who can afford to temporarily forgo wages, other individuals may find such a commitment device unavailable or not preferable for them due to their financial situation. In such a scenario, perhaps an NCC would do the necessary work. Thus, the comparative question must always be alive to the context of specific decisions made by specific employees.

\section{NONCOMPETE CLAUSES FOR THE SAKE OF EMPLOYEES}

Now that we see how NCCs can act as a commitment device, we are better equipped to respond to the objections to NCCs I noted in section two.

In response to the objection from general employee welfare: NCCs can directly advance the interests of employees. By giving an employee a credible signal of commitment, it allows that employee to be better equipped in seeking the sort of firm he or she desires. Additionally, NCCs can advance employee interests in training by incentivizing firms to invest in training.

In response to the objection from tipping the scales: NCCs can advance the bargaining power of employees vis-à-vis their employers. NCCs give employees another bargaining chip in negotiation. As noted, limiting exit options is costly, and this is something employees can press in bargaining. In fact, there is some evidence in the US context that, when NCCs are utilized prior to the employee accepting the job and during the negotiation process, employees see an increase in their wages (Starr, Prescott, and Bishara 2018). This is not surprising from a bargaining perspective.

One might worry that the option of an NCC as an individual choice for bargaining may generate a problem from the perspective of what Debra Satz calls "choice sets" (2008, 274-81). The worry is that sometimes giving individuals a choice generates undesirable outcomes for other people. To use Satz's case, giving people the option to a sell a kidney might be good for the person who wants to sell his/her kidney, but may impact the choices of others who do not want to sell a kidney. Specifically, the option may increase the price of credit for people who are not willing to use a kidney as collateral. Similarly, one might object that giving the option of an NCC in bargaining will make it more expensive for workers who do not want to sign an NCC to find employment.

Whatever the plausibility of this objection in the case of kidney markets, it is far less compelling in the case of NCCs. The main problem with the objection is that it 
rules out too much behavior. Almost all commercial activity has pecuniary externalities of the sort described; for example, by giving the option to sell any asset, this raises the cost of not selling that asset for those who are unwilling to do. As Satz herself notes, markets in second homes have similar pecuniary externalities (2008, 276). Thus, even if this concern from collateral has bite in the case of kidneys due to the possibly special nature of the body, it is far less plausible in the case of other activities.

In response to the objection from limiting options: NCCs, properly understood, can increase freedom, understood as the number of opportunities one has. NCCs can grant access to skills and jobs one might not otherwise have. Yes, it is a reduction of one option, but it is in exchange for other, perhaps more valuable options, depending on the circumstances.

The only objection that the commitment device model of NCCs seems less well equipped to deal with is the objection from domination. Recall that the objection from domination rests on the claim that NCCs, in conjunction with at-will employment, render employees vulnerable to domination. Given that each employee's livelihood is at the mercy of his or her employer's will, this subjects employees to arbitrary power and thus domination. It is not clear that the benefits of NCCs for employees that I noted before deal with this problem. To this extent, a version of the objection to NCCs from unfairness to employees appears to remain standing.

I have a number of responses to the objection from domination. They all take a similar tack. My basic response is that the objection from domination is not an objection to NCCs specifically. Rather, it gets its force either from general, background facts about employment, work, and public policy, or specific features of a particular employee's case.

The objection from domination depends on the claim that being fired threatens an employee's fundamental interests, particularly when that employee is unable to find alternative, comparable employment. An NCC legally makes it the case that an employee is unable to find that alternative employment for a defined period of time and within a defined geographic location. However, NCCs in and of themselves do not render losing a job unacceptable.

First, it is important to note that the NCC is often not for nothing - the employee signs an NCC for consideration. Otherwise, the NCC would be unenforceable. The increased wage can blunt the force of being unable to work in one's chosen profession within the parameters of the NCC. Further, the NCC could build into it a provision that the firm covers financially the period of unemployment through generous severance pay. ${ }^{10}$ Under these circumstances, the severance pay limits how much firing affects the employee's fundamental interests, blunting the seriousness of arbitrary power wielded by managers.

Second, generous government-supplied unemployment benefits, or perhaps even a universal basic income, could serve a similar function (Pettit 2006, 141; Lovett 
2010, 199-203; Taylor 2017, 53-54). Like generous severance pay, these policies protect the employee interests threatened by at will employment, blunting potential domination.

Relatedly, it is not NCCs on their own that create conditions of domination, but NCCs in conjunction with at-will employment. But there is nothing in an NCC that requires at will employment to be the norm. Alternative rules of employment, such as attaching just cause requirements to termination, are perfectly compatible with NCCs. Further, placing just cause constraints on employment solves the problem of domination. This is because the problem of domination is subject to the arbitrary power of another. When the managerial power to terminate is constrained by just cause, that power is no longer arbitrary in the sense that it is no longer exercised solely at the discretion of the manager. It is constrained by various rules and norms.

Finally, and on a related theme, it is true that the power of exit is one way to secure a person against arbitrary power. But it is not the only way (Taylor 2017,11-26). As the economist Albert Hirschmann (1970) famously argued, voice is another way of exercising some kind of control. If the problem with NCCs, in regards to domination, is that they eliminate exit as a check on arbitrary power, a natural response is to substitute exit with voice. Increasing voice appears to be Anderson's preferred solution to the problem of domination within the firm and is, in fact, the argument republicans make for democracy, more generally (Anderson 2017a, 70). By granting formal avenues of voice to those subject to power, one gives those subject to power a way of controlling that power (Pettit 2012). Controlled via voice, this power is no longer arbitrary. Thus, one might think, yet again, it is not that NCCs on their own generate conditions of domination. But rather, it is that NCCs plus a lack of voice generate domination. If a firm that utilized NCCs were more democratically organized, or offered opportunities for employees to have a say in the operation of the firm, this would act as a check on the power of managers. Or, as Lars Lindblom (2019) has recently argued in the context of understanding consent to incomplete contracts, workers can have voice by contesting firm power through the use of unions. With such checks, managerial power would no longer count as arbitrary and therefore no longer count as an instance of domination.

In summation, the objection from domination is not directly addressed by seeing NCCs as commitment devices. Nonetheless, once we properly understand the objection from domination, we can see that it is not so much an objection against NCCs but rather an objection against NCCs given particular background facts that are subject to change, or how NCCs may be used in a particular case.

This conclusion, however, may not save NCCs from the objection from domination. One might worry that linking the dominating character of NCCs to background employment conditions is a pyrrhic victory. After all, many of those background employment conditions presently exist, and many of the policy proposals suggested in remedying them seem far off, if not simply unfeasible (e.g., universal basic income). As Joshua Preiss (2018) points out, focusing on a package of policy proposals as I do here obscures how policy is made in a piecemeal fashion through a messy political process. If my claims that NCCs do not necessarily enable domination are not robust against a wide range of politically feasible outcomes and 
conditions, including current employment conditions, one might wonder whether we should be abolitionists after all.

The problem with this objection is that it homogenizes the labor market in a way that conceals important differences between cases. For example, a background of employment-at-will is the default in common law countries, but not all companies, industries, and countries use this default. Closest to home, universities do not employ their tenured professors at will. Consider further those employees who have significant assets. Such employees' fundamental interests are sheltered from firing in a way that the fundamental interests of the low-wage employee, working paycheck to paycheck, are not. In regards to the realistic possibility of some of the mitigating concerns for NCCs: I pointed out earlier in note 10 that "garden leave" exists in the UK-firms will pay their employees not work. This is functionally equivalent to an NCC, but also reveals how the conditions under which an NCC is not dominating are not merely utopian. I might also point out that firms with some worker governance (while full worker cooperatives are relatively rare, partnerships are less so) and unions exist here and now.

Even if I were to concede the most to the objection-that the background employment conditions that give NCCs their dominating character are prevalent and unlikely to change in the near future-I have nonetheless succeeded in providing a qualified defense of NCCs for two reasons. First, granting this premise would provide a reason to be contingent abolitionists rather than pure abolitionists. A contingent abolitionist would hold that NCCs are permissible in principle, but are impermissible under current circumstances and likely nearby circumstances. Should circumstances suitably change, this would speak in favor of walking back bans against NCCs for the contingent abolitionist. This is distinct from the standard discussion of NCCs, which assumes NCCs are just a tool for employers to dominate employees. More importantly, my view has given some insight into what the relevant contingencies are. Second, granting this objection primarily cuts against my response to the objection from domination. Unless the only value we seek to maximize is non-domination, how problematic NCCs are depends on how we are to weigh non-domination against other possible goods. Thus, even if I were to concede the most, my arguments still provide a qualified defense of NCCs that pushes the conversation forward.

To be clear, this response does not defend all NCCs; I think it would be a mistake to do so. I am offering a qualified defense of NCCs. The benefit of such a defense is that, not only am I able to draw out the virtues of NCCs from the point of view of the employee, but I am also able to give an account of when NCCs fall short and deserve our ire.

\section{AN ETHICS OF NONCOMPETE CLAUSES}

I have argued that NCCs can act as a commitment device to advance the interests of employees. To say that NCCs can act in this way does not mean they do act in this way. In fact, they often do not. In this section, I argue that seeing NCCs as a commitment device provides a clear vantage point from which to evaluate particular 
uses of NCCs. This perspective allows us to differentiate between the Jimmy John's worker and the software engineer, and it gives a broad sense of when it is wrong for employers to use NCCs. The general rule: A specific instance or practice of using an NCC is unjustified when it fails to give employees an opportunity to use the NCC as a bargaining tool. I do not take this rule to provide necessary and sufficient conditions for an NCC to be permissible. The rule works most strongly as a negative test: if the use of an NCC does not provide an opportunity for the employee to use the NCC as a bargaining tool, this gives us a strong reason to be suspicious. However, in light of the arguments in the previous section, I also believe the rule works positively, though not as a sufficient condition. In this positive vein, I take the rule to provide something like what David Schmidtz calls a supporting condition, or "a qualified sufficient condition, qualified in the sense of being a sufficient basis for endorsement in the absence of countervailing conditions" (Schmidtz 2008, 118).

Consider the Jimmy John's case. Our reasons for objecting to the use of NCCs for low-skill, low-wage work are overdetermined. First, these NCCs were given to employees on the first day of work, without access to legal counsel. Second, the NCCs given to Jimmy John's employees were overly broad and likely unenforceable. Finally, for low-wage workers, the cost of exit is high as is, exacerbating worries surrounding domination. Let me go through these features in turn to show how they run afoul of the arguments presented earlier.

Many firms will use NCCs in a way that circumvents the bargaining and negotiating process of employment. For example, firms in the United States will sometimes make employees sign an NCC on the first day of work without the ability to consult a lawyer. The NCC is often presented to the employee without prior notice in a take-it-or-leave-it fashion (Marx 2011, 706). A recent estimate suggests as many as a third of all NCCs in the United States are signed after accepting an offer (Starr 2019). Employees, worried about keeping their new job, tend to sign such NCCs under these unfavorable conditions. Oftentimes, they also do not have an opportunity to seek legal advice. This situation is quite different from circumstances in which an employee is still in negotiation stages and is still considering alternative options. The cost of leaving a new job is higher than the cost of walking away from the negotiating table.

When employers give NCCs after a job offer has been accepted, it is difficult to see how the NCC could be used as bargaining tool or as a credible signal of type. After all, the firm already hired the employee. For this reason, it appears that the practice of springing an NCC on an employee the first day is at odds with the model of NCCs as commitment devices. Instead, this practice appears to be a textbook case of employers using NCCs to advantage their own interests over those of their employees. This not just a theoretical concern, as empirical research in the United States suggests this sort of practice is correlated with lower wages for at least some employees (Balasubramiun et al. 2018). ${ }^{11}$ When firms give NCCs to employees to 
sign on their first day of work or after the employee accepts the offer for employment, they are not giving that employee an opportunity to use the NCC as a commitment device. Firms are, in part, circumventing that opportunity. Thus, this practice is impermissible from the perspective outlined here.

Another feature of the Jimmy John's case that appears objectionable is that the NCC is almost certainly unenforceable. This sort of behavior is not isolated to Jimmy John's; many different firms will have employees sign NCCs that no court would enforce. We have already mentioned how the practice of giving an NCC after the acceptance of an employment offer is likely unenforceable due to lack of consideration. Further, some firms will use NCCs in states, such as California, where the use of such NCCs is severely restricted. This is far from uncommon. An empirical study suggests that whether or not a particular state enforces NCCs makes no difference to the rate of usage by firms in the United States (Prescott, Bishara, and Starr 2016). The worry is that firms are using unenforceable NCCs as a way of intimidating employees who may not know better. Unaware that their NCC is unenforceable, employees will act as though it is enforceable.

As in the case of first-day NCCs, common use of unenforceable NCCs often violates the general rule, the reason being is that unenforceable NCCs appear to exploit information asymmetries between employers and employees. Many employees are ignorant or unaware of the legal enforceability of a given NCC. This, in conjunction with the practice of giving an employee an NCC to sign on his or her first day of work without the ability to speak with a lawyer, does not appear to give the employee an opportunity to use the NCC as a bargaining tool. Thus, as in the case of day-of NCCs, unenforceable NCCs are impermissible under the arguments advanced here. ${ }^{12}$ This usage of NCCs appears to be a way for firms to take advantage of their more sophisticated legal knowledge to advance their interests over that of their employees.

I will entertain, however, the possibility that it is sometimes permissible to use unenforceable NCCs. Suppose we are speaking about a case in which both parties are aware of the unenforceability of an NCC. Let us also assume the NCC is unenforceable because of a state law, such as in California, that renders NCCs legally invalid except in very unusual circumstances. In such cases, I believe that an NCC can nonetheless play a signaling role. To be clear, the signaling role it plays will be limited. Part of what makes the NCC a commitment device ex ante is that it binds the employee ex post. Nonetheless, as a form of cheap talk, it can be somewhat useful. Cheap talk, because it is cheap, is often not a credible signal. But cheap talk can still be used as a signal. ${ }^{13}$ For this reason, there is nothing in principle wrong with 
using unenforceable NCCs so long as they do not exploit information asymmetries between employers and employees regarding the legal validity of such NCCs. This, however, would be quite an unusual situation.

Finally, there are the cases of using NCCs for low-wage work. Much of the public outcry against NCCs seems motivated by their use for low-wage workers. Low-wage work seems the easiest case from an ethical perspective. It is not clear that low-wage workers in firms have access to trade secrets and information that employers are trying to control. Further, low-wage workers tend to already be especially vulnerable to the costs of losing a job. Limiting low-wage employees' ability to find alternative employment only exacerbates this. Because of this, many seem to think that, even if NCCs are permissible under some circumstances, they are not permissible for lowwage work. This concern is reflected in the 2016 Illinois Freedom to Work Act, which specifically targets and prohibits NCCs for low-wage workers. ${ }^{14}$

I agree that there are good reasons to criticize the use of NCCs for low-wage workers. Despite this, I do not see anything in principle that rules out NCCs for lowwage work. If part of what an NCC can do is help match employees to firms on the grounds of what sort of culture the employee prefers, I do not see why this cannot happen for jobs with low-wages. Similarly, there is training involved in low-wage work (even if it is limited). For this reason, firms may be hesitant to invest in training on the basis that these low-wage workers may leave for competing firms after receiving training. In fact, NCCs may be particularly capable of signaling commitment for low-wage, low-skill work. There is nothing that dictates that a costly signal must be in the form of limiting options. An alternative form of a costly signal might be a significant capital investment. However, for low-wage, low-skill work, this alternative is likely not available. Thus, an NCC might provide a way that an employee can utilize a costly signal of commitment in the absence of significant capital holdings (Posner, Triantis, and Triantis 2004).

The issue with the use of NCCs for low-wage work is not that it is for low-wage work, as such. Rather, it is because the position of persons seeking or in low-wage work exacerbates the worries noted earlier. Consider the case that has primarily motivated my analysis: Jimmy John's. This section has outlined numerous ways in which Jimmy John's usage of NCCs fell short of the standard adopted here. What was objectionable about these NCCs is not the fact they were used for low-wage work, but due to these other features. But, again, this is not about whether the job in question is low-wage or not. The fact that a job is low-wage may exacerbate these issues, but it is not what makes the NCC impermissible in a given case.

That being said, perhaps there are good reasons to follow Illinois's lead and be contingent abolitionists regarding NCCs for low-wage work. Even if the use of NCCs for low-wage work is not in principle objectionable, and there may be certain 
advantages for using NCCs as a commitment device for low-wage work, the current background employment conditions may be such that NCCs for low-wage work enable domination. This would push us towards the contingent abolitionism discussed at the end of the previous section, at least for NCCs for low-wage work.

Once we see what motivates the criticism of cases like Jimmy John's, I suggest we are in a better position to appreciate why NCCs appear less worrisome in other cases. Think here of the software engineer, who signs a narrowly tailored, enforceable NCC after legal consultation for additional wages or benefits. There is no information asymmetry or exploitation of ignorance here. There is no surprise NCC on the first day. Rather, the NCC is a part of the ordinary course of bargaining between employee and employer. It is difficult to see anything wrong within this interaction. This is because the NCC played a particular sort of role: it acted as a commitment device that allowed an employee to advance her interests.

\section{CONCLUSION}

In this article, I investigated the ethics of NCCs, or covenants not to compete, in employment contracts. Public criticism of these restrictions focuses on how these restrictions appear to set back the interests of employees for the sake of their employers. This article suggested that seeing NCCs as solely advancing the interests of employers is myopic. By describing the way NCCs can act as a commitment device within the context of negotiation and bargaining, I have argued that these restrictions can be for the sake of employees, rather than against them.

This argument focused on the particulars of NCCs, but I could imagine analogous arguments for other forms of employment contract restrictions, such as nondisclosure agreements. The upshot is that, once we understand how employment contract restrictions can act as a commitment device, this gives us a critical standard to evaluate such practices. Simply, I argued that where employees have an opportunity to use restrictions in the context of negotiation, this gives good reason to believe such restrictions are permissible.

To be clear, I have not here provided a full account of the ethics of noncompete clauses. As I noted in the introduction, my starting point was Adam Smith's dictum that we ought to give priority to the interests of employees over those of employers where they come into conflict. A full account of the ethics of employment restrictions will require tackling other concerns, such as general social welfare or distributive justice. Nonetheless, I hope to have made some progress on a set of issues ethicists have largely neglected.

\section{ACKNOWLEDGEMENTS}

Previous versions of this article were presented at Georgetown University and the University of Pennsylvania. In addition to those audiences, I would like to thank Bruce Barry, Jason Brennan, Nick Cowen, John Hasnas, Michael Kates, Luke Semrau, Ed Soule, Carson Young, and two anonymous reviewers for their comments. 


\section{REFERENCES}

Anderson, Elizabeth. 2015. "Equality and Freedom in the Workplace: Recovering Republican Insights." Social Philosophy \& Policy 31 (2): 48-69.

Anderson, Elizabeth. 2017a. Private Government: How Employers Rule Our Lives (and Why We Don't Talk about It). Princeton, NJ: Princeton University Press.

Anderson, Elizabeth. 2017b. "How Bosses are (Literally) Like Dictators." Vox, September 3, 2017. https://www.vox.com/the-big-idea/2017/7/17/15973478/bosses-dictatorsworkplace-rights-free-markets-unions.

Balasubramanian, Natarajan, Jin Woo Chang, Mariko Sakakibara, Jagadeesh Sivadasan, and Evan Starr. 2018. "Locked In? The Enforceability of Covenants Not to Compete and the Careers of High-Tech Workers." US Census Bureau Center for Economic Studies paper no. CES-WP-17-09; Stephen M. Ross School of Business at the University of Michigan, Research Paper Series no. 1339. http://dx.doi.org/10.2139/ssrn.2905782.

Benn, Stanley. 1988. A Theory of Freedom. Cambridge: Cambridge University Press.

Blake, Harlan M. 1960. "Employee Agreements Not to Compete." Harvard Law Review 73 (4): 625-91.

Brooks, Richard R. W., and Carol M. Rose. 2013. Saving the Neighborhood: Racially Restrictive Covenants, Law, and Social Norms. Cambridge, MA: Harvard University Press.

Carter, Ian. 1999. A Measure of Freedom. Oxford: Oxford University Press.

Dworkin, Gerald. 1982. "Is More Choice Better than Less?" Midwest Studies in Philosophy 7 (1): 47-61.

Eidelson, Josh. 2019. "Labor Groups Petition U.S. FTC to Ban Non-Compete Clauses" Bloomberg. March 20, 2019. https://www.bloomberg.com/news/articles/2019-0320/labor-groups-petition-u-s-ftc-to-prohibit-non-compete-clauses.

Elster, Jon. 1979. Ulysses and the Sirens: Studies in Rationality and Irrationality. Cambridge: Cambridge University Press.

Farley, Najah A. "Regulating Non-Compete Agreements." The Regulatory Review. April 4, 2019. https://www.theregreview.org/2019/04/04/farley-regulating-non-competeagreements/.

Feinberg, Joel. 1984. Harm to Others: The Moral Limits of the Criminal Law. Oxford: Oxford University Press.

Flanigan, Jessica. 2018. "Sweatshops Regulations and Workers' Choices." Journal of Business Ethics 153 (1): 79-94.

Hirschmann, Albert. 1970. Exit, Voice, and Loyalty: Response to Decline in Firms, Organizations, and States. Princeton, NJ: Princeton University Press.

Heath, Joseph. 2014. Morality, Competition, and the Firm: The Market Failures Approach to Business Ethics. Oxford: Oxford University Press.

Heath, Joseph, and Joel Anderson. 2010. "Procrastination and the Extended Will." In The Thief of Time: Philosophical Essays on Procrastination, edited by Chrisoula Andreou and Mark D. White, 233-53. Oxford: Oxford University Press.

Kalleberg, Arne L., and Jørn Rognes. "Employment Relations in Norway: Some Dimensions and Correlates." Journal of Organizational Behavior 21 (3): 315-35.

Kates, Michael. 2015. "The Ethics of Sweatshops and the Limits of Choice.” Business Ethics Quarterly 25 (2): 191-212.

Krugman, Paul. 2018. "Capitalism, Socialism, and Unfreedom.” The New York Times. August 26, 2018. https://www.nytimes.com/2018/08/26/opinion/capitalism-socialism-andunfreedom.html. 
Lindblom, Lars. 2019. “Consent, Contestability, and Unions.” Business Ethics Quarterly 29 (2): 189-211.

Lovett, Frank. 2010. A General Theory of Domination and Justice. Oxford: Oxford University Press.

Macneil, Ian R. 1980. The New Social Contract: An Inquiry into Modern Contractual Relations. New Haven, CT: Yale University Press.

Marx, Matt. 2011. "The Firm Strikes Back: Non-compete Agreements and the Mobility of Technical Professionals.” American Sociological Review 76 (5): 695-712.

Moriarty, Jeffrey. 2009. "Rawls, Self-Respect, and Opportunity for Meaningful Work." Social Theory and Practice 35 (3): 441-59.

Moriarty, Jeffrey. 2011. "Compensation Ethics and Organizational Commitment." Business Ethics Quarterly 24 (1): 31-53.

Moriarty, Jeffrey. 2016. 'Is 'Equal Pay for Equal Work' Merely a Principle of Nondiscrimination?" Economics and Philosophy 32 (3): 435-61.

Niswanatha, Aruna. 2016. "Sandwich Chain Jimmy John's to Drop Noncompete Clauses From Hiring Packets.” The Wall Street Journal. June 21, 2016. https://www.wsj. com/articles/sandwich-chain-jimmy-johns-to-drop-noncompete-clauses-from-hiringpackets-1466557202.

Olson, Mancur. 1971. The Logic of Collective Action. Cambridge, MA: Harvard University Press.

Perillo, Joseph. 2003. Contracts. St. Paul, MN: West Publishing Co.

Pettit, Phillip. 1997. Republicanism: A Theory of Freedom and Government. Oxford: Oxford University Press.

Pettit, Phillip. 2006. "Freedom in the Market." Politics Philosophy \& Economics 5 (2): 131-59.

Pettit, Phillip. 2012. On the People's Terms: A Republican Model and Theory of Democracy. Cambridge: Cambridge University Press.

Prescott, J. J., Norman D. Bishara, and Evan Starr. 2016. "Understanding Noncompetition Agreements: The 2014 Noncompete Survey Project." Michigan State Law Review 2016 (2): 369-464.

Preiss, Joshua. 2014. "Global Labor Justice and the Limits of Economic Analysis." Business Ethics Quarterly 24 (1): 55-83.

Preiss, Joshua. 2018. "Did We Trade Freedom for Credit? Finance, Domination, and the Political Economy of Freedom." European Journal of Political Theory. doi: $10.1177 / 1474885118806693$.

Posner, Eric A., George G. Triantis, and Alexander J. Triantis. 2004. "Investing in Human Capital: The Efficiency of Covenants Not to Compete." University of Chicago Coase-Sandor Institute for Law \& Economics, Olin working paper no. 137; University of Virginia School of Law, Law and Economics Research Paper Series no. 01-08. http://dx.doi.org/10.2139/ssrn.285805.

Rawls, John. 1999. A Theory of Justice: Revised Edition. Cambridge, MA: Belknap Press of Harvard University Press.

Rubin, Paul H., and Paul Shedd. 1981. "Human Capital and Covenants Not to Compete" Journal of Legal Studies 10 (1): 93-110.

Satz, Debra. 2008. "The Moral Limits of Markets: The Case of Human Kidneys." Proceedings of the Aristotelian Society 108 (1): 269-88.

Satz, Debra. 2010. Why Some Things Should Not Be for Sale: The Moral Limits of Markets. Oxford: Oxford University Press. 
Schelling, Thomas. 1960. The Strategy of Conflict. Cambridge, MA: Harvard University Press.

Schmidtz, David. 2008. Person, Polis, Planet. Oxford: Oxford University Press.

Singer, Abraham. 2018a. The Form of the Firm. Oxford: Oxford University Press.

Singer, Abraham. 2018b. "Justice Failure: Efficiency and Equality in Business Ethics." Journal of Business Ethics 149 (1): 97-115.

Smith, Adam. 1976 [1776]. An Inquiry into the Nature and Causes of the Wealth of Nations. Indianapolis, IN: Liberty Fund, Inc.

Starr, Evan. 2019. "Consider This: Training, Wages, and the Enforceability of Covenants Not to Compete." Industrial and Labor Relations Review 72 (4): 783-817.

Starr, Evan, J. J. Prescott, and Norman Bishara. 2018. "Noncompetes in the US Labor Force." University of Michigan Law School, Law and Economics Research Paper Series no. 18-013. http://dx.doi.org/10.2139/ssrn.2625714.

Taylor, Robert S. 2017. Exit Left: Markets and Mobility in Republican Thought. Oxford: Oxford University Press.

Velleman, J. David. 1992. "Against the Right to Die." The Journal of Medicine and Philosophy 17 (6): 665-81.

Zwolinski, Matt. 2007. "Sweatshops, Choice, and Exploitation.” Business Ethics Quarterly 17 (4): 689-727.

HARRISON FrYE is an assistant professor of political science at the University of Georgia. Frye was previously a junior faculty fellow at the Georgetown Institute for the Study of Markets and Ethics. He works on a wide range of topics in normative political theory, including the nature and value of freedom and the justification of economic inequality. 